\title{
PEMBERDAYAAN MASYARAKAT DALAM PENCEGAHAN STUNTING MELALUI BUDAYA GOTONG ROYONG
}

\author{
OLEH : \\ Erwina Sumartini, Septi Nurawaliyah, Faridatul Aima, Rita Hermawati, Susi Susanti, \\ Shania Isfanni \\ (erwinasumartini5@gmail.com )
}

\section{A. DASAR PEMIKIRAN}

Indonesia merupakan salah satu negara berkembang yang sedang menghadapi masalah stunting. Stunting merupakan suatu kondisi kegagalan mencapai perkembangan fisik yang diukur berdasarkan panjang/tinggi badan menurut umur. Batasan stunting menurut WHO jika tinggi badan menurut umur berdasarkan Z-score sama dengan atau kurang dari -2 SD di bawah rata-rata standar (Widianti YA. 2017). Faktorfaktor yang menyebabkan stunting diantaranya; gangguan pertumbuhan janin sejak dalam kandungan yang berlanjut setelah lahir, pemberian ASI eksklusif yang kurang optimal, pemberian makanan tambahan yang tidak adekuat dan pengendalian infeksi (WHO, 2014).

Pada tahun 2017 terdapat 22,2\% atau sekitar 150,8 juta balita di dunia mengalami stunting, setengah balita stunting di dunia besaral dari Asia (55\%) sedangkan sepertiganya $39 \%$ dari Afrika. Menurut WHO Indonesia termasuk kedalam Negara ketiga dalam prevalensi tertinggi regional Asia Tenggara. rata-rata prevalensi stunting di Indonesia tahun 2005-2017 adalah 36,4\% (kemenkes RI, 2018). Proporsi balita dengan status gizi sangat pendek dan pendek di Indonesia pada tahun 2018 yaitu sebesar 29,9\%, status gizi kurus dan sangat kurus sebesar 10,2\% (Riskesdas, 2018). Angka tersebut masih melebihi batas non public health $\mathrm{WHO}$ yaitu 20\%. Sehingga perlu dilakukan berbagai upaya untuk bisa menurunkan kejadian stunting untuk masa depan Indonesia yang lebih baik.

Stunting merupakan suatu kondisi yang memiliki dampak luar biasa terhadap kehidupan balita di masa yang akan datang. Hasil penelitian SV Subrahmanian, Ivan Mejla-Guevara dan Aditi Khrishna (2016) menyatakan bahwa Stunting yang terjadi pada awal kehidupan dapat menyebabkan kerusakan yang permanen (irreversible) - Penelitian Sandjaja, Poh BK, Rojroonwasinkul N, Le Nyugen BK, Budiman B, Ng LO, Soonthorndhada K, et al (2013) menyatakan bahwa anak dengan nilai $\mathrm{Z}$ score rendah menurut $\mathrm{BB} / \mathrm{U}$ kemungkinan memiliki IQ non verbal < $89 \quad 3,5$ kali lebih besar. Begitupun dengan anak yang memiliki IMT/U dan TB/U rendah berpeluang memiliki IQ non verbal <89. hasil penelitian tersebut didukung oleh Yadika AND, Berawi KN, Nasution SH (2019) yang menyatakan bahwa Terdapat hubungan yang signifikan antara stunting dengan IQ sebagai salah satu tanda perkembangan otak, dimana skor IQ pada anak stunting lebih rendah dibandingkan dengan anak non stunting. Tergangguan pertumbuhan otak dapat menyebabkan anak dengan stunting memiliki prestasi pendidikan menurun, lama pendidikan menurun dan 
pendapatan yang rendah merupakan salah satu dampak yang mungkin akan dialami oleh anak dengan stunting. Selain itu anak dengan stunting tumbuh menjadi dewasa yang kurang berpendidikan, miskin, serta kurang sehat karena banyak mengalami penyakit non menular seperti obesitas, diabetes mellitus, hipertensi pada masa dewasa (WHO, 2014)

Balita stunting di daerah pedesaan memiliki proporsi yang lebih besar yaitu sekitar $40 \%$ dibandingkan dengan daerah perkotaan sekitar 33\%. Salah satu karakteristik yang dimiliki masyarakat Indonesia adalah gotong royong dalam menangani masalah yang ada di masyarakat. Masyarakat pedesaan sangat memegang teguh prinsip gotong royong dalam menangani masalah yang terjadi, sehingga gotong royong dapat dijadikan sebuah pendekatan dalam memecahkan masalah stunting yang terjadi di pedesaan.

Posyandu merupakan salah satu bentuk upaya kesehatan bersumber daya masyarakat (UKBM) yang dikelola dan diselenggarakan dari, oleh, untuk dan bersama masyarakat dalam penyelenggaraan pembangunan kesehatan, guna memberdayakan masyarakat dan memberikan kemudahan kepada masyarakat dalam memperoleh pelayanan kesehatan dasar untuk mempercepat penurunan angka kematian ibu dan bayi. UKBM merupakan wahana pemberdayaaan masyarakat, yang dibentuk atas dasar kebutuhan masyarakat, dikelola oleh, dari, untuk dan bersama masyarakat, dengan bimbingan dari petugas Puskesmas, lintas sektor dan lembaga terkait lainnya (Kemenkes RI dan POKJANAL, 2011).

Pelaksanaan posyandu memiliki hambatan diantaranya masyarakat masih beranggapan penimbangan balita kurang memberikan manfat. Sebagian besar masyarakat menilai bahwa untuk mengetahui berat badan balita tidak perlu susah mendatangi posyandu asalkan tersedia timbangan (Susanto F, Claramita M dan handayani S, 2017). kondisi tersebut mengakibatkan peran serta masyarakat terhadap kegiatan posyandu kurang baik dan berpotensi menimbulkan masalah yaitu tidak terpantaunya pertumbuhan balita sehingga ketika terjadi masalah gizi orang tua tidak dapat melakukan penanganan lebih dini.

Pemberdayaan masyarakat adalah segala upaya fasilitasi yang bersifat non instruktif, guna meningkatkan pengetahuan dan kemampuan masyarakat, agar mampu mengidentifikasi masalah yang dihadapi, potensi yang dimiliki, merencanakan dan melakukan pemecahannya dengan memanfaatkan potensi setempat. Pemberdayaan masyarakat di bidang kesehatan adalah proses pemberian informasi kepada individu, keluarga atau kelompok (klien) secara terus menerus dan berkesinambungan mengikuti perkembangan klien, serta proses membantu klien, agar berubah dari tidak tahu menjadi tahu atau sadar (aspek pengetahuan atau knowledge), dari tahu menjadi mau (aspek sikap atau attitude), dan dari mau menjadi mampu melaksanakan perilaku yang diperkenalkan (aspek tindakan atau practice) (Kemenkes RI dan POKJANAL, 2011). Menurut Harahap (2012: 78) dalam Ratoyo (2019) menyatakan bahwa pemberdayaan (empower) memiliki dua pengertian, yaitu (1) to give power atau authority to atau memberi kekuasaan, mengalihkan kekuatan atau mendelegasikan otoritas ke pihak lain. (2) to give ability to atau 
enable atau usaha untuk memberi kemampuan atau keperdayaan.

Upaya pengembangan kualitas sumberdaya manusia dengan mengoptimalkan potensi tumbuh kembang anak dapat dilaksanakan secara merata, apabila sistem pelayanan kesehatan berbasis masyarakat seperti posyandu dapat dilakukan secara efektif dan efisien dan dapat menjangkau semua sasaran yang membutuhkan layanan kesehatan (Kemenkes RI dan POKJANAL, 2011).

Berdasarkan hasilo penimbangan balita pada bulan agustus 2018 di Desa Singasari Kecamatan Singaparna kabupaten Tasikmalaya terdapat 21 balita dengan kategori pertumbuhan sangat pendek dan 67 balita dengan kategori pertumbuhan pendek dari total jumlah 365 balita. Berdasarkan hasil pengkajian data kegiatan pada kegiatan survey masawas diri (SMD) Desa Singasari Kecamatan Singaparna Kabupaten Tasikmalaya pada bulan Januari 2019 yang disajikan dalam kegiatan musyawarah masyarakat desa (MMD) Desa Singasari kecamatan Singaparna Kabupaten Tasikmalaya pada bulan Januari 2019 didapatkan data bahwa partisipasi masyarakat pada kegiatan posyandu masih kurang, selain itu fasilitas bangunan posyandu belum memadai, masih ada beberapa posyandu yang terpaksa menggunakan gedung madrasah untuk melaksanakan hari buka posyandu. Untuk menyelesaikan permasalah diatas perlu dilaksanakannya kegiatan pemberdayaan masyarakat Desa Singasari Kecamatan Singaparna Kabupaten Tasikmalaya untuk menyelesaikan masalah melalui kegiatan pengabdian kepada masyarakat dengan tema "Pemberdayaan Masyarakat dalam Deteksi Dini Balita Stunting".

\section{B. TUJUAN}

1. Tujuan Umum:

Memfasilitasi masyarakat dalam mencegah masalah balita stunting di Desa Singasari Kecamatan Singaparna Kabupaten Tasikmalaya melalui kegiatan gotong royong.

2. Tujuan Khusus:

a. Melakukan pemberdayaan masyarakat melalui kegiatan gotong royong untuk menyediakan gedung posyandu

b. Melakukan pemberdayaan masyarakat melalui kegiatan gotong royong untuk melakukan deteksi dini stunting pada balita

\section{BENTUK KEGIATAN}

Metode pelaksanaan dalam kegiatan pemberdayaan masyarakat ini adalah focus group discussion (FGD) dan partisipasi masyarakat. Populasi adalah kader posyandu, tokoh masyarakat, tokoh agama, kepala desa singasari dan bidan desa singasari. Kegiatan pemberdayaan masyarakat dalam deteksi dini balita stunting diantranya; tahap pertama, peningkatan pengetahuan tokoh masyarakat melalui kegiatan pemaparan materi mengenai pentingnya posyandu sebagai sarana untuk memantau pertumbuhan balita yang diikuti oleh 10 orang tokoh masyarakat. Tahap kedua, melaksanakan focus group discussion (FGD) untuk merumuskan penyelesaian masalah mekanisme penyediaan prasarana posyandu berupa gedung bagi posyandu yang masih menggunakan gedung madrasah dan pemberdayaan tokoh masyarakat dalam mendukung ibu untuk memantau pertumbuhan balita ke posyandu. 


\section{SASARAN}

Sasaran dalam kegiatan pengabdian kepada masyarakat ini adalah masyarakat yang diwakili oleh kader kesehatan dan ketua RT di Desa Singasari Kecamatan Singaparna Kabupaten Tasikmalaya sejumlah 10 orang.

\section{E. TEMPAT DAN WAKTU}

Tempat pelaksanaan kegiatan pengabdian kepada masyarakat di Desa Singasari Kecamatan Singparna Kabupaten Tasikmalaya. Kegiatan pengabdian kepada masyarakat dilaksanakan pada Januri 2019

\section{F. PELAKSANA}

Pelaksana dalam kegiatan pengabdian kepada masyarakat ini adalah dosen dan mahasiswa. Dosen berperan dalam membuat perencanaan, bersama bidan desa melaksanakan kegiatan FGD dengan menjadi fasilitator kegiatan tersebut, serta mengevaluasi kegiatan pengabdian kepada masyarakat. Sedangkan mahasiswa terlibat dalam proses pelaksanaan kegiatan diantaranya memberikan penyuluhan kepada tokoh masyarakat mengenai pentingnya posyandu sebagai sarana untuk memantau pertumbuhan balita.

\section{G. HASIL KEGIATAN DAN PEMBAHASAN}

\section{Hasil Kegiatan}

a. Tahap satu dilaksanakan peningkatan pengetahuan tokoh masyarakat melalui kegiatan pemaparan materi mengenai pentingnya posyandu sebagai sarana untuk memantau pertumbuhan balita. Setelah dilaksanakan pemaparan materi, tokoh masyarakat menyatakan bahwa sangat penting untuk memanfaatkan posyandu untuk memantau pertumbuhan balita.

b. Melaksanakan focus group discussion (FGD) untuk merumuskan penyelesaiaan masalah mekanisme penyediaan prasarana posyandu berupa gedung posyandu bagi posyandu yang masih menggunakan gedung madrasah dan pemberdayaan tokoh masyarakat dalam mendukung ibu untuk memantau pertumbuhan balita ke posyandu. Hasil dari kegiatan di tahap dua diantaranya; dilaksanakan gerakan seribu (GEBU) untuk menyediakan gedung posyandu yaitu gerakan pengumpulan uang sebesar seribu rupiah dari masyarakat yang akan dikoordinir oleh para RT masing-masing, serta keterlibatan langsung tokoh masyarakat dalam mendukung ibu untuk mengunjungi posyandu melalui mekanisme;

1) Tokoh masyarakat (Kader/Ketua RT) akan membantu mengumumkan hari buka posyandu kepada seluruh masyarakat

2) Tokoh masyarakat (Ketua RT dan kader kesehatan) menjaring balita yang mengalami masalah pertumbuhan dan tidak rutin melakukan kunjungan ke posyandu dengan melaporkan langsung kepada bidan desa untuk ditindak lanjuti dengan skrining pertumbuhan

3) Tokoh masyarakat (Ketua RT dan kader kesehatan) memantau balita yang 
mengalami masalah berdasarkan hasil skrining

\section{Pembahasan}

Stunting merupakan suatu kondisi kegagalan pertumbuhan linier pada balita sebagai dampak terjadinya kegagalan pertumbuhan intra uterine yang berlanjut dengan kegagalan pertumbuhan ekstra uterine. Stunting merupakan suatu kondisi yang perlu segera diperbaiki sebelum anak berusia 2 tahun, karena pada saat anak melewati usia dua tahun, sudah terlambat untuk memperbaiki kerusakan yang terjadi pada tahuntahun awal (Unicef Indonesia, 2012). Stunting merupakan prediktor buruknya kualitas sumberdaya sebuah bangsa, sehingga masalah ini harus menjadi prioritas untuk diselesaikan melalui upaya pencegahan dan penanganan.

Upaya kesehatan bersumber daya masyarakat (UKBM) merupakan bentuk umum wadah pemberdayaan masyarakat di bidang kesehatan, salah satunya Posyandu. Kader posyandu merupakan penggerak utama seluruh kegiatan yang dilaksanakan di posyandu. keberadaan kader penting dan strategis untuk menggalang kepedulian dan partisipasi masyarakat (Megawati G, Wiramihardja S, 2019).

Menurut Wiku Adisamito yang dikutip oleh Restuastuti T, dkk (2017) menyatakan bahwa pemberdayaan masyarakat merupakan proses yang dilakukan oleh masyarakat (dengan atau tanpa campur tangan pihak luar) untuk memperbaiki kondisi lingkungan, sanitasi dan aspek lainnya yang secara langsung maupun tidak langsung berpengaruh dalam kesehatan masyarakat. Dalam upaya pemberdayaan masyarakat, terdapat empat unsur pokok yang perlu diperhatikan yaitu aksesibilitas informasi, keterlibatan dan partisipasi, akuntabilitas dan kapasitas organisasi lokal, agar tercapai tujuan pemberdayaan masyarakat.

Indonesia merupakan suatu negara yang memiliki kekhasan yaitu gotong royong. Budaya tersebut merupakan warisan nenek moyang yang perlu dilestarikan, salah satunya dalam menyelesaikan sebuah masalah. Menurut pranadji (2009) gotong royong dapat dimaknai sebagai pemberdayaan masyarakat, karena bisa menjadi modal sosial untuk membentuk kekuatan kelembagaan di tingkat komunitas, masyarakat negara serta masyarakat lintas bangsa dan negara dalam mewujudkan kesejahteraan. Hal tersebut dikarenan di dalam gotong royong terkandung makna collective action to struggle, self governing, common goal, dan sovereignity (Irfan M, 2017). Gotong royong digunakan sebagai cara untuk menyelesaikan masalah oleh masyarakat Desa Singasari Kecamatan Singaparna kabupaten Tasikmalaya dalam menyelesaikan masalah kurangnya ketersediaan fasilitas gedung posyandu yang menjadi salah satu faktor pendukung dalam berjalannya kegiatan pemantauan pertumbuhan balita. Berdasarkan hasil FGD tokoh masyarakat yang diwakili oleh kader dan RT menyepakati akan dilaksanakan gerakan seribu (GEBU). Gerakan 
ini merupakan suatu upaya masyarakat dalam menggalang dana untuk membangun gedung poyandu bagi posyandu yang masih menggunakan fasilitas gedung madrasah untuk melaksanakan kegiatan posyandu. Pengumpulan dana akan dilaksanakan setiap minggu dan di koordinir oleh kader dan RT. Gerakan seribu merupakan salah satu bentuk pemberdayaan masyarakat yang akan menjadi kekuatan bagi Desa Singasari dalam menyediakan fasilitas gedung posyandu.

Langkah lain yang dilakukan dalam pemberdayaan masyarakat melalui gotong royong adalah melibatkan ketua RT dan kader kesehatan dalam memberikan informasi kapan hari buka posyandu. Informasi yang diberikan bertujuan mengingatkan masyarakat untuk bersiap-siap mengondisikan waktu untuk berkunjung ke posyandu, selanjutnya ketua RT bersama kader kesehatan menjaring balita yang tidak datang ke posyandu serta balita yang mengalami keluhan masalahan pertumbuhan untuk segera dilakukan skrining oleh bidan, tahap terakhir adalah melibatkan masyarakat dalam memantau balita yang dinyatakan mengalami masalah berdasarkan hasil skrining.

\section{H. KESIMPULAN DAN SARAN}

Pemberdayaan masyarakat dalam deteksi dini balita stunting di desa Singasari Kecamatan Singaparna Kabupaten Tasikmalaya akan dilaksanakan melalui kegiatan "gerakan seribu (GEBU)" dan keterlibatan langsung tokoh masyarakat dalam melakukan penjaringan balita yang mengalami masalah pertumbuhan di masing-masing wilayah.

\section{DAFTAR PUSTAKA}

Irfan M. 2017. Metamorfosis Gotong Royong Dalam Pandangan Konstruksi Sosial. Prosiding KS: Riset \& PKM.

Kemenkes RI, Pokjanal Posyandu. 2011. Pedoman Umum Pengelolaan Posyandu. Jakarta. Kementerian Kesehatan RI.

Kemenkes RI. 2018. Riset Kesehatan Dasar (Riskesdas). Jakarta. Badan Penelitian dan Pengembangan

Kemenkes RI. 2018. Situasi balita Pendek (Stunting) di Indonesia. Buletin Jendela data dan Informasi Kesehatan. Kementerian Kesehatan Pusat Data dan Informasi. Jakarta. ISSN 2088-270 X, semester I (hal 1)

Ratoyo. 2019. Strategi Pemberdayaan Masyarakat Dalam Penanganan Kasus Stunting di Kampung Tulung Kanan kecamatan Bumi Ratu Nuban Kabupaten Lampung Tengah. Jurnal Simplex Vol. 2 No. 3 Desember 2019

Restuastuti T, dkk. 2017. Analisis Pemberdayaan masyarakat di Bidang Kesehatan. Jurnal Kesehatan Melayu.

Sandjaja, Bee Koon Poh, Nipa Rojroonwasinkul, et al.2013. Relationship between anthropometric indicators and cognitive performance in Southeast Asian school-age children. British Journal of Nutrition, 110, S57-S64 
Susanto F, Claramita M dan handayani S. 2017. Peran Kader Posyandu dalam pemberdayaan masyarakat Bintan. Journal of Community Medicine and public health. Vol. 33 No. 1 hal 33-41

S V Subramanian, Ivan Mejla-Guevara and Aditi Khrishna.2016. Rethinking policy perspective on childhood stunting: time to formulate a structural and multifactorial strategy. Maternal \& Child Nutrition published by jhon wiley \& sons Ltd maternal \& Child Nutrition. 12 (suppl.I), pp.236.

Unicef Indonesia. 2013. Ringkasan kajian Gizi Ibu dan Anak, Oktober 2012. Diunduh dari: http://www.unicef.org.

WHO.2014. WHA Global Nutrition Targets 2025 : Stunting Policy Brief.

Widianti YA. 2017. Prevalensi, Faktor Risiko, dan Dampak Stunting Pada Anak Usia Sekolah. JITIPARI (Jurnal Ilmiah Teknologi dan Industri Pangan UNISRI)

Yadika ADN, Berawi KN, Nasution SH. 2019. "Pengaruh stunting terhadap perkembangan kognitif dan prestasi belajar". Majority. 273-282.

\section{J. DOKUMENTASI}
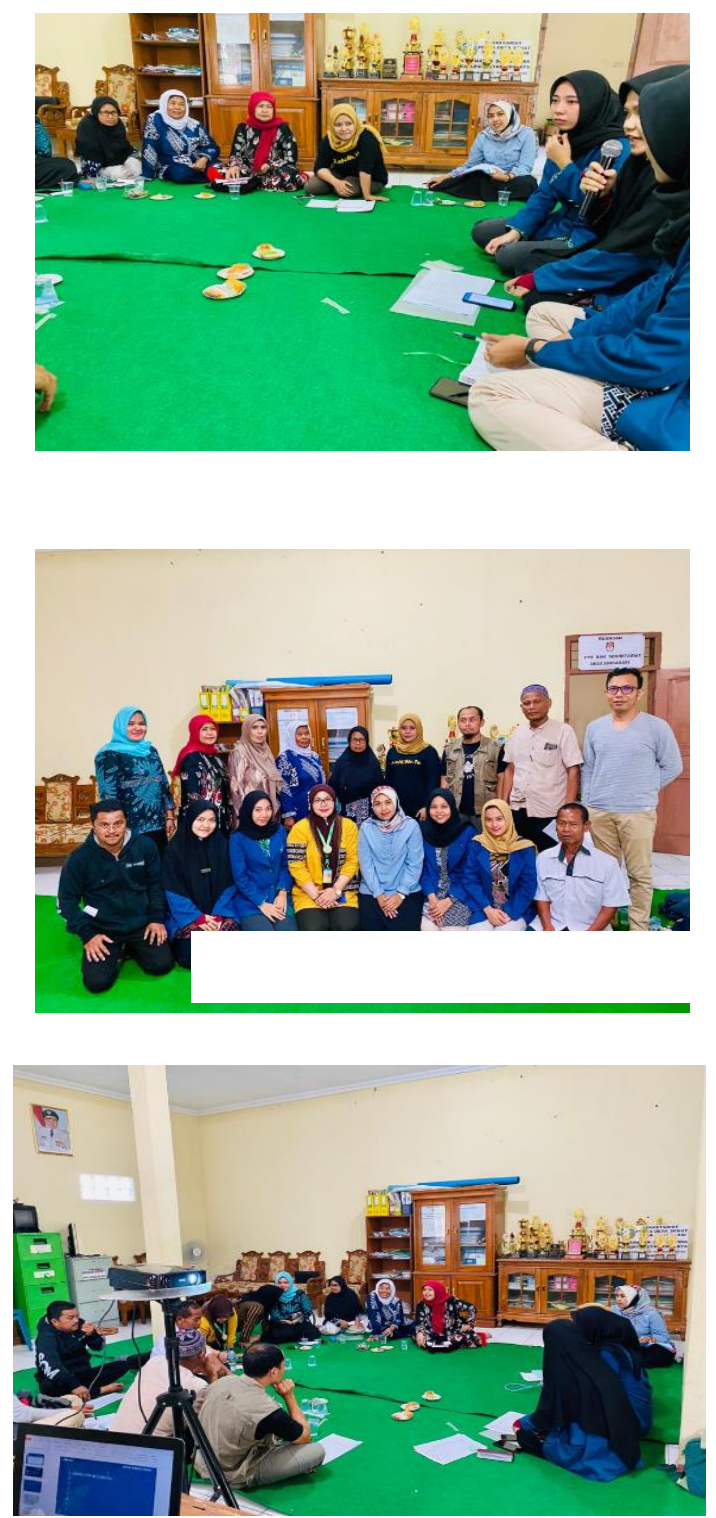